\title{
USO DE CIANAMIDA HIDROGENADA E ÓLEO MINERAL NA FLORAÇÃO, BROTAÇÃO E PRODUÇÃO DO PESSEGUEIRO 'CHIRIPÁ'1
}

\author{
IDEMIR CITADIN², MARCELO HENRIQUE BASSANI ${ }^{3}$, MOESES ANDRIGO DANNER ${ }^{3}$, SERGIO MIGUEL MAZARO², \\ ALFREDO DE GOUVÊA ${ }^{2}$
}

RESUMO - O frio acumulado em regiões de inverno ameno é insuficiente para superar a dormência de algumas cultivares de pessegueiro, como o Chiripá, sendo necessária a utilização de produtos químicos para melhorar a brotação, a floração e a produção. O objetivo deste trabalho foi avaliar o efeito de diferentes doses de cianamida hidrogenada $\left(\mathrm{CH}_{2} \mathrm{~N}_{2}\right)$ e óleo mineral $(\mathrm{OM})$ na floração, brotação e produção do pessegueiro cv. Chiripá, cultivado no município de Pato Branco. O uso de $1 \% \mathrm{CH}_{2} \mathrm{~N}_{2}$ combinada com $1 \%$ de OM antecipa, aumenta e uniformiza a floração, a brotação e a colheita de pessegueiro cv. Chiripá, promovendo maior frutificação efetiva e produção por planta, viabilizando o plantio comercial dessa cultivar. Termos para indexação: endodormência, necessidade de frio, superação da dormência, compensadores de frio, Prunus persica.

\section{USE OF HYDROGEN CYANAMID AND MINERAL OIL IN BLOOMING, BUDDING AND PRODUCTION OF PEACH 'CHIRIPÁ'}

\begin{abstract}
The chilling accumulated in areas of mild winter climate is not enough to overcome the endodormancy of some cultivars, like 'Chiripá', being necessary the use of chemical products for a better budding, blooming and cropping. The objective of this work was to evaluate the effect of different doses of hydrogen Cyanamid $\left(\mathrm{CH}_{2} \mathrm{~N}_{2}\right)$ and mineral oil (MO) in the blooming, budding and production of peach tree, cv. Chiripá cultivated in Pato Branco, Paraná. The use of $1 \% \mathrm{CH}_{2} \mathrm{~N}_{2}$ combined with $1 \%$ of MO, increase, anticipate and homogenize blooming, budding and cropping of peach tree cv. Chiripá, promoting larger fruit set and production per plant, making possible the commercial orchards of this cultivar.
\end{abstract}

Index terms: endodormancy, chilling requirement, break dormancy, cold compensators, Prunus persica.

\section{INTRODUÇÃO}

A superação natural da dormência das plantas caducifólias envolve fatores internos, como o balanço dos promotores e inibidores de crescimento, e fatores externos, como a temperatura, o fotoperíodo e a radiação solar, entre outros. O acúmulo de frio durante o inverno é fundamental para que plantas dessas espécies possam brotar e florescer normalmente. Quando cultivadas em regiões com insuficiência de frio hibernal, as frutíferas caducifólias apresentam sintomas erráticos, como atraso e maior duração do período de floração e menor percentual de floração e brotação, resultando em redução na produção, com frutos desuniformes e de baixa qualidade, características de plantas mal adaptadas (Marodin et al., 1992). Nestes casos, a utilização de produtos químicos, que promovam e uniformizem a brotação e a floração, é prática comum na viabilização dos cultivos de frutíferas de clima temperado. Porém, nem sempre os resultados são satisfatórios, sobretudo em locais onde ocorre baixo acúmulo de frio (Miele et al., 1998; Nachtigal \& Camelatto, 1997). Associações de óleo mineral e sais de dinitro foram as mais utilizadas na superação artificial da dormência das frutíferas temperadas no Brasil (Petri et al., 1996). Com a proibição do uso dos sais de dinitro, a melhor opção para a superação artificial da dormência passou a ser a utilização de cianamida hidrogenada $\left(\mathrm{CH}_{2} \mathrm{~N}_{2}\right)$, associados ou não ao óleo mineral $(\mathrm{OM})$.

As regiões situadas em zona de transição mesoclimática, ou seja, regiões limítrofes de climas $\mathrm{Cfa}$ e $\mathrm{Cfb}$ de Koopen, caracterizam-se por oscilações de temperatura durante o inverno, com riscos de ocorrência de geadas tardias (agosto e setembro), sendo comum, também, a ocorrência de granizo localizado. Tais fenômenos têm contribuído para a redução da produtividade das frutíferas de caroço nestas regiões, sobretudo cultivares de baixa necessidade de frio e de florescimento precoce. Uma das possibilidades de cultivo de pessegueiros são as cultivares de florescimento tardio, porém tal característica está estreitamente ligada à necessidade de frio da cultivar, ou seja, quanto maior a necessidade maior a profundidade da dormência e mais tardiamente ocorrerá a brotação e a floração, reduzindo os riscos de danos por geadas ou granizos de final de inverno e início de primavera. Por outro lado o frio acumulado nestas regiões nem sempre é suficiente para superar a dormência de algumas cultivares, como o
Chiripá, sendo necessária a utilização de algumas técnicas artificiais para amenizar este problema.

O objetivo deste trabalho foi avaliar o efeito de diferentes doses de cianamida hidrogenada e óleo mineral na floração, brotação e produção do pessegueiro cv. Chiripá, cultivado na região de Pato Branco-PR, caracterizada por apresentar inverno ameno e riscos de geadas tardias.

\section{MATERIAL E MÉTODOS}

O experimento foi conduzido em 2003 e 2004, em pomar comercial de pessegueiro da cv. Chiripá, com 3 e 4 anos de idade, respectivamente, localizado no município de Pato Branco, Paraná, coordenadas $26^{\circ} 07^{\prime} \mathrm{S}$, $52^{\circ} 41^{\prime} \mathrm{O}$ e altitude de $700 \mathrm{~m}$. A média do acúmulo de horas de frio abaixo de $7{ }^{\circ} \mathrm{C}$ é de 224 horas (maio a outubro de 1979 a 2003), sendo que o menor registro foi de 76 horas, em 1998, e o maior de 346 horas, em 1990. A temperatura média é de $18,7^{\circ} \mathrm{C}$.

Os produtos utilizados nos tratamentos para superação de dormência foram cianamida hidrogenada $\left(\mathrm{CH}_{2} \mathrm{~N}_{2}\right)$ e óleo mineral $(\mathrm{OM})$. A aplicação foi feita com pulverizador pressurizador de $\mathrm{CO}_{2}$ com gasto médio de 1 litro de calda por planta. As condições ambientais estavam favoráveis nos dias da aplicação dos produtos, apresentando umidade relativa do ar acima de $60 \%$ e temperatura média diurna em torno de $20^{\circ} \mathrm{C}$.

O delineamento experimental utilizado foi em blocos ao acaso, com 4 repetições, com duas plantas por parcela, cinco ramos por planta e 6 tratamentos: T1) $0,5 \%$ de $\mathrm{CH}_{2} \mathrm{~N}_{2}+1,0 \%$ de OM; T2) $0,5 \%$ de $\mathrm{CH}_{2} \mathrm{~N}_{2}$ +2,0\% de OM; T3) $1,0 \%$ de $\mathrm{CH}_{2} \mathrm{~N}_{2}+1,0 \%$ de OM; T4) $1,0 \% \mathrm{de} \mathrm{CH}_{2} \mathrm{~N}_{2}+$ $2,0 \%$ de OM; T5) $0 \%$ de $\mathrm{CH}_{2} \mathrm{~N}_{2}+2,0 \%$ de OM; T6) $0 \% \mathrm{de} \mathrm{CH}_{2} \mathrm{~N}_{2}+0 \%$ de OM (testemunha).

Os tratamentos foram aplicados no dia 24 de julho de 2003 e 26 de julho de 2004, com as gemas em estádio de dormência (estádio fenológico A) e frio acumulado de 141 horas e 113 horas abaixo de $7^{\circ} \mathrm{C}$, respectivamente. $\mathrm{O}$ frio acumulado foi mensurado em estação meteorológica oficial pertencente ao IAPAR, localizada no município de Pato Branco.

Todos os tratos culturais necessários foram realizados segundo Raseira et al. (1998), adaptados às condições de solo da região.

Para fins de avaliação, foram amostrados cinco ramos mistos,

\footnotetext{
${ }^{1}$ (Trabalho 157/2005). Recebido: 04/10/2005. Aceito para publicação: 04/04/2006.

${ }^{2}$ Eng $^{\circ}$ Agrônomo, UTFPR, Campus Pato Branco, PR 465, Km 01, C.Postal 571, 85501-970. idemir@pb.cefetpr.br

${ }^{3}$ Alunos de Graduação do Curso de Agronomia, UTFPR, Campus Pato Branco.
} 
de ano, do terço médio da periferia de cada planta, não sofrendo poda de desponte, resultando em 10 ramos avaliados por parcela. Em cada ano do experimento, foram avaliados os percentuais de brotação e floração, baseados no número total de gemas vegetativas e floríferas, respectivamente. Estas análises foram feitas aos 13;27 e 67 dias após a aplicação dos tratamentos, em 2003, e aos 13; 27 e 38 dias, em 2004, para verificar o início, a plena e o final da brotação e da floração. A frutificação efetiva e a brotação final foram mensuradas em 2004, aos 60 dias após a aplicação dos tratamentos T1, T2, T3, T4, e aos 80 dias para T5 e T6. Em 2004, foi realizado o raleio de frutos nas plantas que apresentavam muita carga, de modo homogêneo, conforme descrito por Raseira et al. (1998). Nas plantas que receberam os tratamentos com $\mathrm{CH}_{2} \mathrm{~N}_{2}$, o raleio foi mais intenso, devido à maior frutificação efetiva. Neste ano, avaliaramse também a produção e o peso médio de frutos por planta. Os dados foram transformados em arco-seno da raiz de $\mathrm{x} / 100$ e submetidos à análise de variância, sendo as médias comparadas pelo teste Duncan ( $P$ d" $0,05)$.

\section{RESULTADOS E DISCUSSÃO}

No ano de 2003, aos 13 dias após a aplicação, as plantas que receberam os tratamentos T3 e T4, apresentavam 36\% e 28\% de floração, respectivamente (Figura 1-A). A plena floração (53\%) foi observada 27 dias após a aplicação, no segundo decêndio de agosto, época de menor probabilidade de ocorrência de geadas na região em estudo (IAPAR, 2000), minimizando riscos de perdas na produção. As plantas que receberam os tratamentos T1 e T2 também apresentaram a plena floração 27 dias após a aplicação, porém com percentual de floração de $35 \%$, significativamente menor que T3 e T4. Os tratamentos T5 e T6 proporcionaram os menores percentuais de floração, não diferindo entre si, com a plena floração ocorrendo aos 67 dias, não superando os $10 \%$ de floração (Figura 1-A).

Em 2004, a plena floração, em todos os tratamentos, ocorreu aos 38 dias após a aplicação, não superando 35\%. Nesta época, não foram observadas diferenças significativas entre os tratamentos, exceto para T6 (testemunha), que apresentou o menor percentual de floração $(10 \%)$. Neste ano, a maior frutificação efetiva foi observada nas plantas que receberam o tratamento $3(25 \%)$, sem diferir significativamente de T4 (20\%) e T2 (19\%), porém diferindo de T1 (18\%), T5 (13\%) e T6 (5\%), que apresentou o menor percentual significativo de frutificação (Figura $1-B)$.

Em 2003, o efeito positivo da maior dose de OM sobre a floração foi observado somente entre os tratamentos T1 (15\%) e T2 (21\%), aos 13 dias após a aplicação (Figura 1-A). Nestes tratamentos, a concentração de $\mathrm{CH}_{2} \mathrm{~N}_{2}$ foi a mesma (0,5\%). Já em 2004, ano de menor acúmulo de frio, o efeito de maiores doses de OM sobre a floração foi mais expressivo, observado no tratamento T2, comparado com T1, aos 27 dias após a aplicação, e T5 em relação a T6, aos 38 dias após a aplicação. A diminuição no percentual de floração foi observada entre os tratamentos T3 e T4, aos 27 dias após a aplicação. Neste caso, a maior dose de OM (T4 - 2,0\% de OM) contribuiu para diminuir o percentual de floração quando comparado com T3 $(1,0 \%$ de OM). Observou-se também um efeito significativo e positivo do OM sobre a frutificação efetiva entre os tratamentos T5 (2,0\% de OM) e T6 (sem OM) (Figura 1-B).

O maior percentual de floração em 2003, em relação a 2004, é atribuído ao maior acúmulo de frio ocorrido antes ( 141 horas abaixo de $\left.7{ }^{\circ} \mathrm{C}\right)$ e após (177 horas abaixo de $\left.7{ }^{\circ} \mathrm{C}\right)$ a aplicação dos tratamentos,

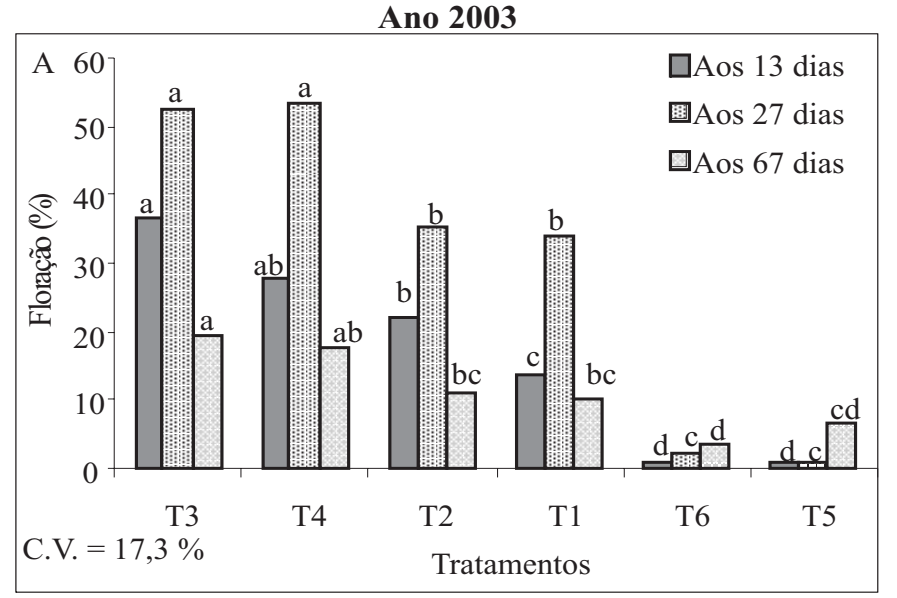

Ano 2003

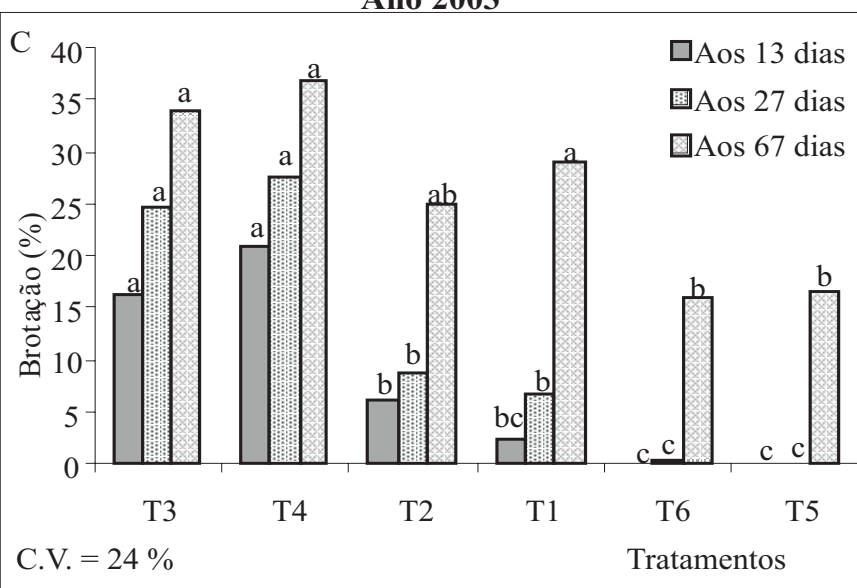

Ano 2004

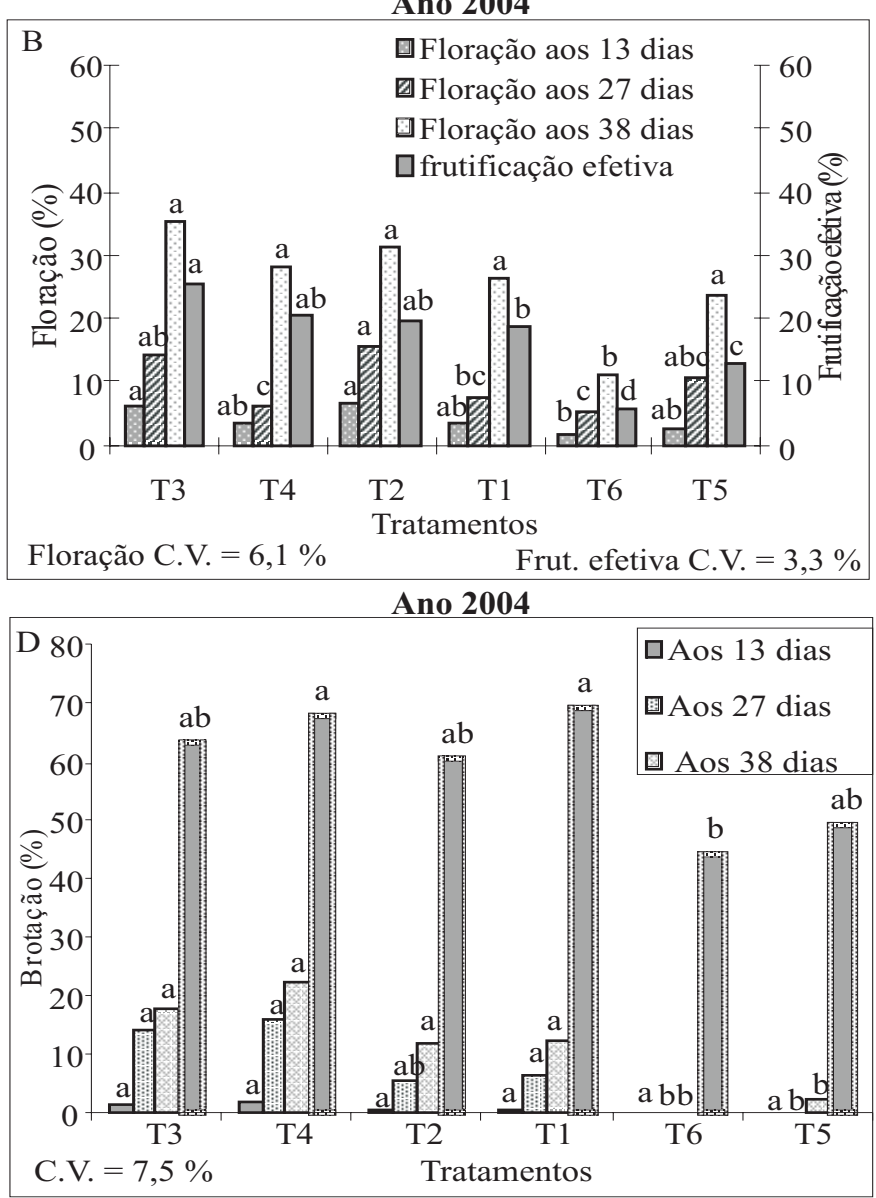

FIGURA 1 - Percentagem de floração e brotação analisadas aos 13; 27 e 67 dias em 2003 (A e C) e 13; 27 e 38 em 2004 (B e D), após o tratamento com diferentes doses de cianamida hidrogenada $\left(\mathrm{CH}_{2} \mathrm{~N}_{2}\right)$ e óleo mineral $(\mathrm{OM})$ em pessegueiro 'Chiripá'. A frutificação efetiva e a brotação final foram avaliadas após os 60 dias da aplicação, em 2004. Médias de tratamento dentro de cada época, seguidas por letras minúsculas distintas, diferem entre si pelo teste Duncan a $P \mathrm{~d} \leq 0,05$. T1) $0,5 \%$ de $\mathrm{CH}_{2} \mathrm{~N}_{2}+1,0 \%$ de OM; T2) $0,5 \%$ de $\mathrm{CH}_{2} \mathrm{~N}_{2}+2,0 \%$ de OM; T3) $1,0 \%$ de $\mathrm{CH}_{2} \mathrm{~N}_{2}+1,0 \%$ de OM; T4) $1,0 \%$ de $\mathrm{CH}_{2} \mathrm{~N}_{2}+2,0 \%$ de OM; T5) $0 \%$ de $\mathrm{CH}_{2} \mathrm{~N}_{2}+2,0 \%$ de OM; T6) $0 \%$ de $\mathrm{CH}_{2} \mathrm{~N}_{2}+0 \%$ OM (testemunha). UTFPR, Câmpus Pato Branco-PR. 
totalizando 318 horas de frio acumulado até o final do mês de setembro de 2003. Em 2004, além de ter ocorrido menor acúmulo de frio antes da aplicação dos tratamentos (113 horas abaixo de $\left.7^{\circ} \mathrm{C}\right)$, após a aplicação, houve um período relativamente longo de estiagem e calor, que se seguiram praticamente até aos 38 dias após a aplicação dos tratamentos, o que pode ter potencializado a queda de gemas floríferas nos tratamentos que receberam óleo mineral associado ou não a $\mathrm{CH}_{2} \mathrm{~N}_{2}$, conforme ilustra a Figura 2.

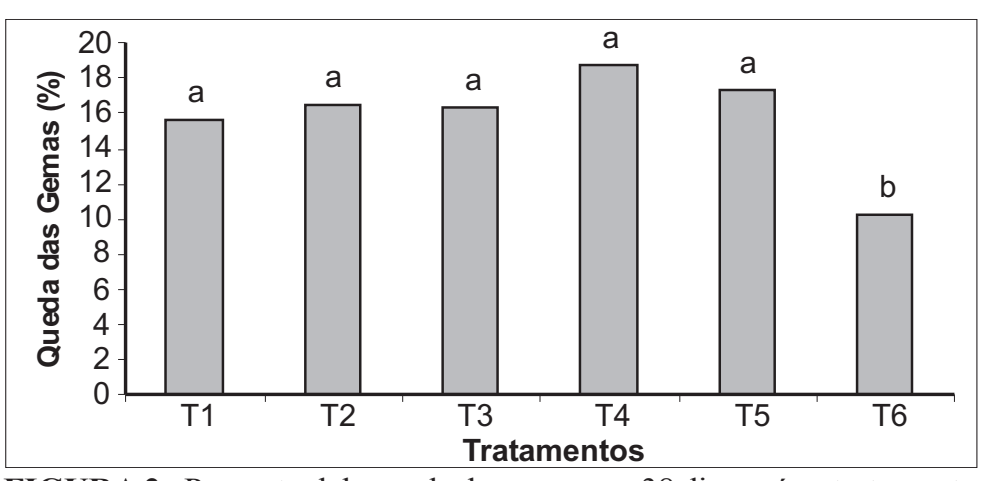

FIGURA 2 - Percentual de queda de gemas aos 38 dias após o tratamento com diferentes doses de cianamida hidrogenada $\left(\mathrm{CH}_{2} \mathrm{~N}_{2}\right)$ e óleo mineral (OM) em pessegueiro 'Chiripá', em 2004. Médias dos tratamentos seguidas por letras minúsculas distintas diferem entre si, pelo teste Duncan, a $P \mathrm{~d} \leq 0,05$. T1) $0,5 \%$ de $\mathrm{CH}_{2} \mathrm{~N}_{2}+1,0 \%$ de OM; T2) $0,5 \%$ de $\mathrm{CH}_{2} \mathrm{~N}_{2}+$ 2,0\% de OM; T3) $1,0 \%$ de $\mathrm{CH}_{2} \mathrm{~N}_{2}+1,0 \%$ de OM; T4) $1,0 \%$ de $\mathrm{CH}_{2} \mathrm{~N}_{2}+2,0 \%$ de OM; T5) $0 \%$ de $\mathrm{CH}_{2} \mathrm{~N}_{2}+2,0 \%$ de OM; T6) $0 \%$ de $\mathrm{CH}_{2} \mathrm{~N}_{2}+0 \% \mathrm{OM}$ (testemunha). UTFPR, Câmpus Pato Branco-PR.

$\mathrm{O}$ modo de ação da $\mathrm{CH}_{2} \mathrm{~N}_{2}$ não é bem conhecido, e algumas hipóteses foram elaboradas. Uma hipótese é que a $\mathrm{CH}_{2} \mathrm{~N}_{2}$ provoque uma elevação na concentração de peróxido de hidrogênio, ocasionando a indução de processos bioquímicos de destruição do peróxido produzido e a ativação do ciclo das pentoses, induzindo a superação da dormência (Omran, 1980; Nir \& Shulman, 1984; Shulman et al., 1986). Porém, em situações em que não haja a indução desses processos, poderá haver um acúmulo de peróxido de hidrogênio tóxico nas gemas, acarretando a queda das mesmas. Situações de estresse hídrico, ocasionadas por estiagem prolongada, ou mesmo longos períodos com temperaturas elevadas, após a aplicação, conforme observado em 2004, poderiam ter induzido o acúmulo de peróxido de hidrogênio e a queda das gemas floríferas. Silveira (2003) demonstrou que as cultivares de pessegueiro apresentam diferenças de sensibilidade das gemas floríferas a $\mathrm{CH}_{2} \mathrm{~N}_{2}$. Segundo Erez (1995), aplicações de $\mathrm{CH}_{2} \mathrm{~N}_{2}$ muito cedo podem não trazer os benefícios desejados, enquanto tardiamente podem provocar a queda de gemas. Fallahi \& Willemsen (2002) citam a $\mathrm{CH}_{2} \mathrm{~N}_{2}$ como agente de raleio químico, quando aplicada na fase de botão com ponta rosada.

Quanto à brotação, em 2003, as plantas que receberam os tratamentos T3 e T4, apresentaram os maiores percentuais de brotação aos 13; 27 e 67 dias após a aplicação, percentuais significativamente superiores aos demais tratamentos, exceto em relação a T1 e T2, aos 67 dias (Figura 1-C). Houve uma nítida antecipação de brotação nos tratamentos T3 e T4 em relação aos demais tratamentos. Os maiores percentuais de brotação, em 2003, foram atingidos nos tratamentos T3 (34\%) e T4 (37\%), aos 67 dias após a aplicação dos tratamentos, não diferindo de T2 (25\%) e T1 (28\%), mas superior à testemunha (T6) e T5, ambos com $16 \%$ de brotação (Figura 1-C). Nesta época, houve acúmulo de 318 horas de frio abaixo de $7{ }^{\circ} \mathrm{C}$ (registro da estação metereológica do IAPAR, Pato Branco)

Em 2004, houve a maior antecipação de brotação nos tratamentos que receberam $\mathrm{CH}_{2} \mathrm{~N}_{2}$ (T3, T4, T2 e T1) em relação a T6 (testemunha) e T5 (2\% de OM). Na brotação final, após 60 dias da aplicação, ocorreu homogeneidade entre os tratamentos, exceto para a testemunha (T6), que apresentou o menor percentual de brotação (44\%), diferindo dos tratamentos T1 e T4 (Figura 1-D).

Nas duas safras, foi observada ocorrência simultânea do início da floração e da brotação nos tratamentos com $\mathrm{CH}_{2} \mathrm{~N}_{2}$ A plena floração, porém, ocorre antes da plena brotação (Figura 1). Segundo Erez (1995), a aplicação de concentrações elevadas de $\mathrm{CH}_{2} \mathrm{~N}_{2}$ pode fazer com que a brotação ocorra antes da floração em frutíferas de caroço, fato não observado neste experimento. Silveira (2003) observou a ocorrência simultânea destes eventos, em experimentos envolvendo $\mathrm{CH}_{2} \mathrm{~N}_{2}$ e OM.

Não foi observado efeito positivo entre as doses de $1 \%$ e $2 \%$ de OM na brotação do pessegueiro cv. Chiripá. Porém, conforme já descrito, o efeito positivo do OM foi observado sobre a floração, principalmente em 2004, ano de menor acúmulo de frio. Sabe-se que existem diferenças entre gemas vegetativas e floríferas quanto à necessidade de frio para superar a endodormência, sendo que as gemas vegetativas apresentam maior necessidade que as gemas floríferas. Assim, o efeito substituto do frio pelo OM pode ter sido eficiente para gemas floríferas, porém não o foi para as gemas vegetativas.

Estes resultados assemelham-se com o descrito por Marodin et al. (2002), que observaram antecipação na brotação do pessegueiro cv. Flamecrest, utilizando diferentes doses de $\mathrm{CH}_{2} \mathrm{~N}_{2}$. O mesmo não foi constatado por Nunes et al. (2001), que não comprovaram antecipação da brotação com relação à testemunha, em pessegueiro cv. Chiripá, no Rio Grande do Sul.
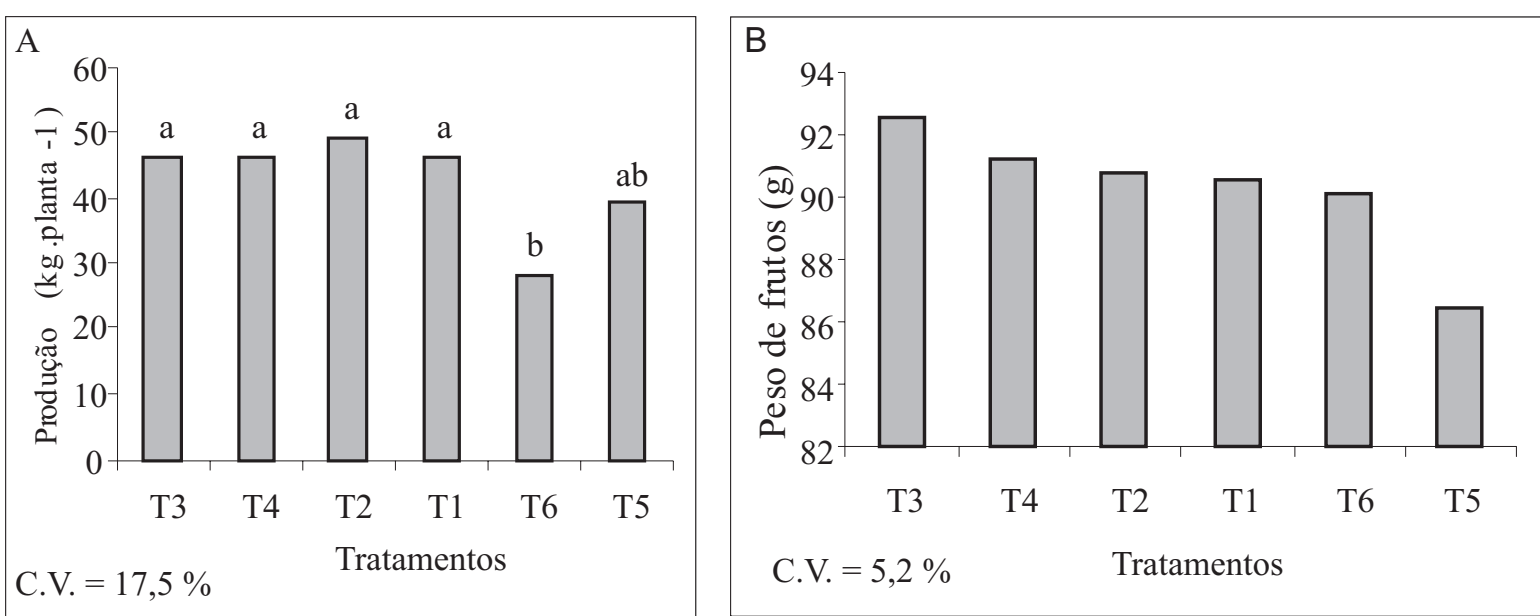

FIGURA 3 - Produção (A) e peso médio de frutos (B) de pessegueiro 'Chiripá' submetido a diferentes doses de cianamida hidrogenada e óleo mineral. Médias dos tratamentos seguidas por letras minúsculas distintas diferem entre si, pelo teste Duncan, a $P \mathrm{~d} \leq 0,05$. Coeficiente de variação $17,5 \%$ e 5,2\% para produção e peso médio de frutos, respectivamente. T1) $0,5 \%$ de $\mathrm{CH}_{2} \mathrm{~N}_{2}+1,0 \%$ de OM; T2) $0,5 \%$ de

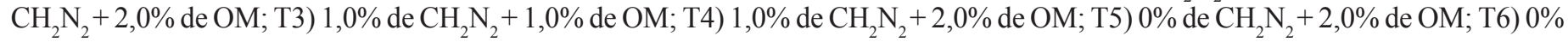
de $\mathrm{CH}_{2} \mathrm{~N}_{2}+0 \% \mathrm{OM}$ (testemunha). UTFPR, Câmpus Pato Branco-PR. 


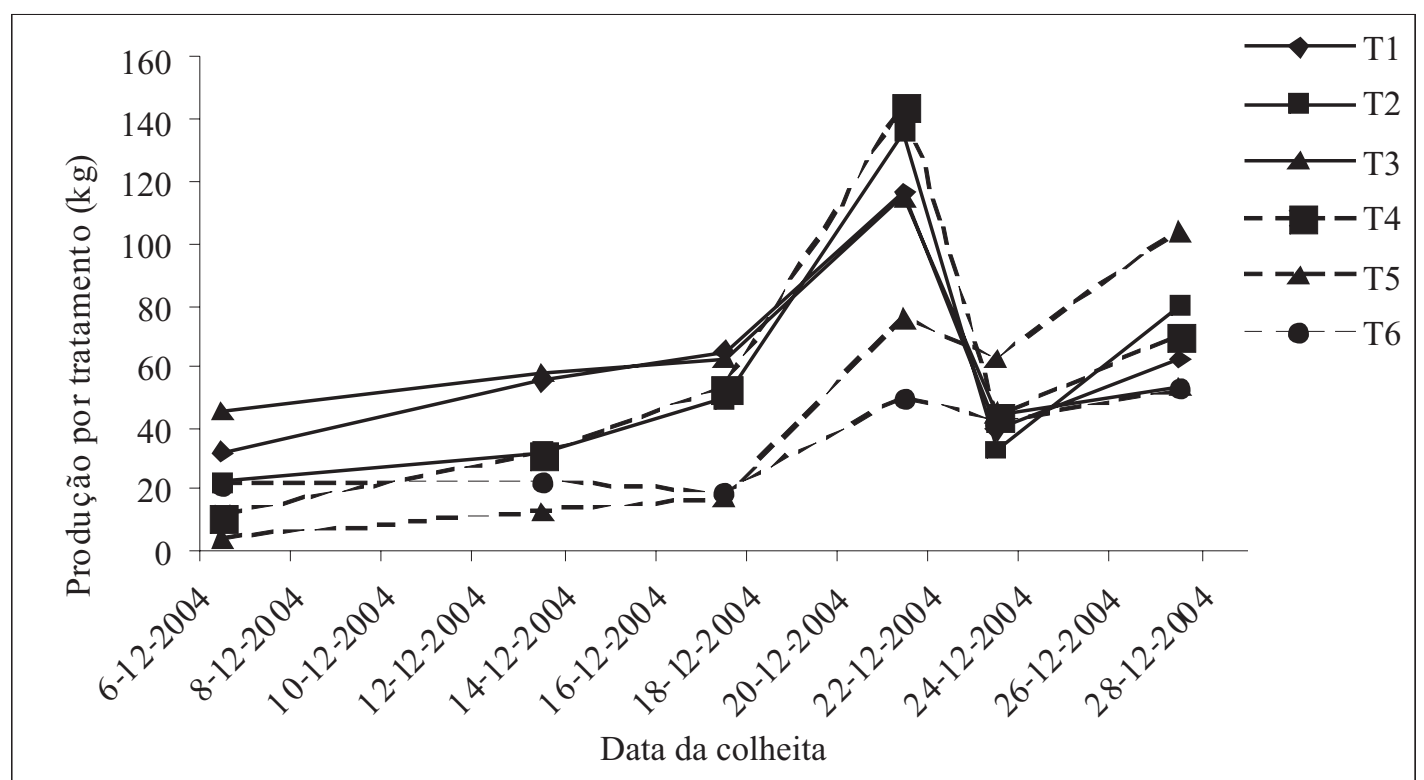

FIGURA 4 - Produção de frutos de pessegueiro cv. Chiripá em cada período de colheita, nos diferentes tratamentos. T1) $0,5 \%$ de $\mathrm{CH}_{2} \mathrm{~N}_{2}+1,0 \%$ de OM; T2) $0,5 \%$ de $\mathrm{CH}_{2} \mathrm{~N}_{2}+2,0 \%$ de OM; T3) $1,0 \%$ de $\mathrm{CH}_{2} \mathrm{~N}_{2}+1,0 \%$ de OM; T4) $1,0 \%$ de $\mathrm{CH}_{2} \mathrm{~N}_{2}+2,0 \%$ de OM; T5) $0 \%$ de $\mathrm{CH}_{2} \mathrm{~N}_{2}+2,0 \%$ de OM; T6) $0 \%$ de $\mathrm{CH}_{2} \mathrm{~N}_{2}+0 \%$ OM (testemunha). Cada tratamento é representado pela soma da produção de oito plantas. UTFPR, Câmpus Pato Branco-PR.

Mesmo tendo sido realizado raleio mais intenso nas plantas que receberam os tratamentos com $\mathrm{CH}_{2} \mathrm{~N}_{2}$ (T1, T2, T3 e T4), observouse maior produção nesses tratamentos, quando comparados com a testemunha (T6), porém não diferindo das tratadas com óleo mineral (T5) (Figura 2-A). Esse resultado está relacionado com o menor percentual de floração nos tratamentos T5 e T6, o qual induz a uma menor frutificação efetiva e, conseqüentemente, a uma menor produção.

Não foram observadas diferenças significativas entre tratamentos quanto ao peso médio dos frutos (Figura 3-B).

Os tratamentos que receberam $\mathrm{CH}_{2} \mathrm{~N}_{2}$, anteciparam o pico de colheita em uma semana, comparado àqueles que não receberam $\mathrm{CH}_{2} \mathrm{~N}_{2}$ (T5 e T6) (Figura 4), em desacordo com os trabalhos de Nunes et al. (2001), que não observaram antecipação na produção.

\section{CONCLUSÃO}

Nas condições em que foi conduzido o experimento, pode-se concluir que o uso de cianamida hidrogenada a $1 \%$, combinada com óleo mineral a 1\%, aumenta, antecipa e uniformiza a floração, a brotação e a colheita do pessegueiro cv. Chiripá, promovendo maior frutificação efetiva e produção por planta, viabilizando o plantio comercial desta cultivar.

\section{REFERÊNCIAS}

EREZ, A. Means to compensate for insufficient chilling to improve bloom and leafing. Acta Horticulturae, Kyoto, n.395, p.81-95, 1995.

FALLAHI,E.; WILLEMSEN, K.M. Blossom thinning of pome and stone fruit. HortScience, Alexandria, v.37, n.3, p.474-476, 2002.

IAPAR (Instituto Agronômico do Paraná). Cartas Climáticas do Paraná, Versão 1.0, 2000 (CD ROM).

MARODIN, G. A. B.; FRANCISCONI, A. H. D.; GALLOIS, E. S. P. Efeito de produtos químicos na quebra de dormência e produção de Pereira (Pyrus communis, L.) cv. Packham's Triumph. Revista Brasileira de Fruticultura, Cruz das Almas, v.14, n.1, p.155 - 160, 1992.

MARODIN, G.A.B.; SARTORI, I.A.; GUERRA, D.S. Efeito da aplicação de cianamida hidrogenada e óleo mineral na quebra de dormência e produção do pessegueiro 'flamecrest'. Revista Brasileira de Fruticultura, Jaboticabal, v.24, n.2, p.426-430, 2002.
MIELE, A.; RIZZON, L.A.; DALL'AGNOL, I. Efeito da época e do número de aplicações de cianamida hidrogenada e óleo mineral na quebra de dormência da videira. Revista Brasileira de Fruticultura, Cruz das Almas, v.20, n.2, p.183-187, 1998.

NACHTIGALL, G.R.; CAMELATTO, D. Efeito da mistura de nitrato de cálcio com thidiazuron, cianamida hidrogenada e óleo mineral na superação da dormência de macieiras (Malus domestica, Borkh.) cv. Gala. Revista Brasileira de Fruticultura, Cruz das Almas, v.19, n.3, p.275-282, 1997.

NIR, G.; SHULMAN, Y. The involvement of catalase in the dormancy of grapevine buds. In: Bud dormancy in grapevines: potential and practical uses of hydrogen cyanamide on grapevines. Davids: University of California, 1984. p. 40-43.

NUNES, J.L.S.; MARODIN, G.A.; SARTORI, I.A. Cianamida hidrogenada, thidiazuron e óleo mineral na quebra da dormência e na produção do pessegueiro cv. Chiripá . Revista Brasileira de Fruticultura, Jaboticabal, v.23, n.3, p. 493-496, 2001.

OMRAN, R.G. Peroxide levels and activities of catalase, peroxidase, and indoleacetic acid oxidase during and after chilling of cucumber seedlings. Plant Physiology, v.65, p.407-408, 1980.

PETRI, J.L.; PALLADINI, L.A.; SCHUCK, E.; DUCROQUET J.H.J.; MATOS, C.S.; POLA, A.C. Dormência e indução da brotação de fruteiras de clima temperado. Florianópolis: Epagri, 1996. 110p.

RASEIRA, A.; PEREIRA, J.F.M.; MEDEIROS, A.R.M.; CARVALHO, F.L.C. Instalação e manejo do pomar. In: MEDEIROS, C.A.B.; RASEIRA, M.C.B. A cultura do pessegueiro. Brasília: EmbrapaSPI; Pelotas: Embrapa-CPACT, 1998. 350p.

SHULMAN, Y.; NIR, G.; LAVEE, S. Oxidative processes in bud dormancy and the use of hydrogen cyanamide in breaking dormancy. Acta Horticulturae, The Hague, v.179, p.141-148, 1986.

SILVEIRA, C.A.P. Avaliação do efeito das horas de frio, épocas de aplicação e concentrações de cianamida hidrogenada e óleo mineral na brotação, floração e frutificação efetiva de pessegueiro em condições de inverno subtropical. 2003, 89p. Tese (Doutorado em Agronomia - Fruticultura de Clima Temperado), Faculdade de Agronomia Eliseu Maciel, Universidade Federal de Pelotas, 2003. 